\title{
From Woohwang Cheongsimwon (牛黄淸心元)* to Ginseng (人參) \\ - The History of Medicine Use in the Joseon Era -**
}

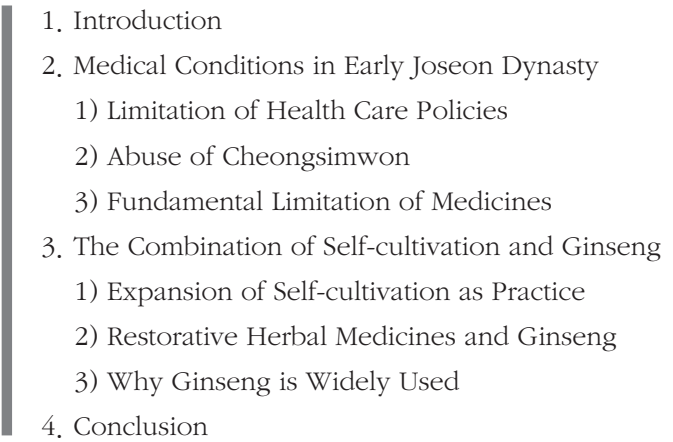

\section{Introduction}

The average life expectancy of Korean people during the Joseon era (1392-1910) was about 35 years. Because infant death rates were so high, longevity was a matter of luck. The average lifespan of Korean kings was much longer, as it has been estimated at about 47 years, but only six lived longer than 60 years. The king who lived the longest was Yeongjo (英祖).

\footnotetext{
* Henceforth written as Cheongsimwon.

** This work was supported by the National Research Foundation of Korea Grant funded by the Korean Government (NRF-2012-8-1486)

*:*: Seoul National University, Seoul, KOREA

E-mail: imsskim@snu.ac.kr
} 
KIM Seong-su: From Woohwang Cheongsimwon (牛黄淸心元) to Ginseng (人蒋)

- The History of Medicine Use in the Joseon Era -

He reigned for 52 years and died when he was 83 years old. He was originally weak, but he lived long thanks to thorough health management. When he was elderly, he used ginseng (人衤) as a restorative herb medicine, and it is said that he ate more than 100 geun (approximately $40 \mathrm{~kg}$ ) between the ages of 59 and $73 .{ }^{1)}$

The Korean summer is very hot and humid, causing people to sweat a lot and rapidly exhaust their physical strength. For these reasons, Korean people habitually eat different kinds of health foods to increase their stamina and manage their health during the summer. Of the health foods used to improve stamina, Samgyetang (氽鷄湯) which is prepared by boiling chicken with medicinal herbs, such as ginseng and astragali radix (黃芪), is a representative choice due to both its high protein content and the efficacy of its medicinal herbs, including ginseng.

When was ginseng first popularly used in Korean history, and what is the history of this use? As noted earlier in the introductory quote, Yeongjo, a king during the 18th century in the late Joseon era, is famous for living a long time, and his secret for longevity was said to be ginseng. However, before the Joseon era, the culture of invigorating oneself and utilizing 'restorative herbs' (Boyak 補藥), ${ }^{2)}$ such as ginseng, was not common. Invigoration and the wide use of restorative herbs to maintain health -prior to the outbreak of a disease- was a cultural phenomenon that first appeared in the field of medicine in Korea in the 18th century.

This medicinal culture, represented by restorative herb medicines, was

1) "King Yeongjo, who ate ginseng for a long time, a king who lived long in the Joseon era," Hankuk Ilbo, 17 July 2014

2) Boyak (補藥) is the medicine used to strengthen the physiology of "five viscera and six entrails' and to maintain a health. In modern medicine, it is considered to strengthen the immune systems. 
the result of combination of developments in medical studies -beginning in the early Joseon era- and changes in social medical systems. This article explores the development and popularization of the cultural phenomenon of medical use during the Joseon era, particularly from the 15th century to the 18th century. During this period, Joseon adopted China's advanced medicinal practices and empirically merged them with its own medicinal practices, which had been widely used since ancient times (Kim, 1993: 206226). The state also established policies for handling people's health care, improving medical institutions, educating doctors, and managing drugs on a kingdom-wide scale (Kim, 1993: 234-238; Son, 1988: 177-184).

This paper examines the changes in the Joseon Dynasty's use of medicines two representative medicines: Cheongsimwon and Ginseng. Since the largest problem with Joseon's medical system was securing highquality doctors, Cheongsimwon was widely preferred by patients because its ability to cure various symptoms. Similarly, ginseng was widely used as a vitalizing medicine, especially during the late Joseon period. The purpose of this study is to clarify that the cause of this phenomenon was the change in the medical market due to the appearance of commercial physicians in the limited state-controlled medical system, as well as change in medical theory. Although Joseon developed a system to educate doctors, this system was limited in its ability to cultivate enough doctors to serve the entire nation. ${ }^{3)}$ However, as the commercialization of medicine progressed during the late Joseon Dynasty, many physicians appeared and began to compete. As a result, preferences for perceptions of medicine

3) For these reasons, numerous Confucian doctors appeared and treated patients. Moreover, in internal rural areas, local intellectuals organized fraternities and autonomously managed community hospitals (Lee, 1988: 264-278; Shin, 2006b: 9-15). 
KIM Seong-su: From Woohwang Cheongsimwon (牛黄淸心元) to Ginseng (人蓼)

- The History of Medicine Use in the Joseon Era -

also changed.

\section{Medical Conditions in the Early Joseon Dynasty}

\section{1) Limitation of Health Care Policies}

Those who lived during the Joseon era were exposed to a variety of diseases that have now disappeared, as well as many that still exist. Now forgotten infectious diseases, such as scarlet fever, were rampant, as were many diseases that have now been reduced and controlled through improved hygiene and improved provision of the necessities of life. This was the case with the Yangban (兩班), society's upper class. Mukjae ilgi (默齋日記), the diary written by Lee Mun-geon (李文楗) who was exiled to Seongju (星州), Gyeongsang-do (慶向道), a southern region of Joseon, in the mid-16th century, illustrates the circumstances at this time (Kim, 2001: 49-54; Shin, 2014: 406-411).

Lee Mun-geon not only recorded diseases, but also personally participated in patient treatment. He took drugs every day to maintain his health, and he treated severe coughs, dysentery, and other infectious diseases in others. Furthermore, he functioned in many ways as a doctor: people asked his counsel regarding treatments, and he frequently treated himself (Shin, 2014: 387-405). Lee Mun-geon's role as a doctor was largely due to his personal achievements and knowledge, but it also reflects the important phenomenon caused by the shortage of doctors during the Joseon era (Kim, 2001: 31-38; Shin, 2014: 457-459).

Following its foundation, Joseon had established Hyeminguk (惠民 局 the Public Medical Office) as a medical institution for residents of the capital and made several other healthcare adjustments and improvements 
(Son, 1988: 177-184). But one area that suffered from this doctor shortage was Hanyang (漢陽), the nation's capital and its political, economic, and cultural center. For example, King Taejo (太祖) Jeonuigam (典醫監 the Palace Medical Office), Oh Gyeong-wu (吳慶祐) and Yang Hong-dal (楊弘達), from Hanyang because they did not immediately participate in treatment of Taejo. ${ }^{4)}$ Eventually, Jeong Do-jeon (鄭道傳), who was pivotal in the operation of the government, requested that the exile be lifted due to the shortage of Hanyang, and the king accepted his request. ${ }^{5}$ As this story illustrates, the shortage of doctors was a serious problem in Hanyang.

This situation gradually improved due to improvements in the state's institutions. Joseon developed a system for nurturing doctors and strengthening medical education, as well as a system (Uiseo seupdoggwan, 醫書習讀官） to select intelligent sons of yangban and have them study medicine (Son, 1988: 203-210). However, such policies did not achieve sufficient qualitative or quantitative improvements in the doctor shortage phenomenon, as evidenced by the following article from King Sejong (世 宗)'s era.

Ijo (吏曹 the Ministry of Personnel) reported to the king, “Those who study medicine just make efforts to read books with prescriptions in them, take an exam, and achieve promotion. They are not interested in treating diseases. Therefore, please recruit them with reference to their score in treatment as well." Then the king did $\mathrm{so}^{6}$

Yejo (禮曹 the Ministry of Rites) reported to the king based on the report from the Palace Medical Office: “...Doctors should

4) Taejo silrok (太祖實錄 Annals of King Taejo), v.12, 22 October 1397.

5) Taejo silrok, v.12, 19 December 1397.

6) Sejong silrok (世宗實錄 Annals of King Sejong), v.11, 18 March 1421. 
KIM Seong-su: From Woohwang Cheongsimwon (牛黄淸心元) to Ginseng (人衤)

- The History of Medicine Use in the Joseon Era -

be precise and proficient in practicing their medical techniques, but local students do not solely study medicine. Therefore, even though they are Euisaeng (醫生 medical students), they are not proficient in preparing medicine and treating illnesses. ${ }^{77}$

At the time, across the whole country, very few received medical education. The prescribed quotas for medical students educated at the Palace Medical Office and the Public Medical Office, located in Hanyang, were 50 and 30, respectively, and in local provinces, this number ranged from 8 to 16 depending on the size of the administrative districts. In sum, the nation was home to only a few hundred medically trained professionals (Shin, 2004a: 207-210), ${ }^{8}$ and the number of doctors employed by the government who were able to continuously perform their tasks was only about three per year (Son, 1988: 210-212). However, it is likely that some medical students who did not have an opportunity to pass the national exam to become health officials still practiced medicine.

Another concern was how efficiently this education and nurturing of doctors was provided. A variety of articles show that positive evaluation of this topic is difficult. ${ }^{9}$ According to the records above, although medical education was provided to nurture doctors for national medical institutions, the educational process suffered from many shortcomings. Most of all, due to the educational policy's dependence on exams, students were unable to develop proper clinical capabilities.

7) Sejong silrok, v.28, 3 May 1425.

8) About 250 personnel, including medical officials, medical students, and female physicians, provided medical service across Korea until the late $19^{\text {th }}$ century.

9) In the late 15th century, Yang Seong-ji (梁誠之) stated that students undertaking medical services in rural districts were numerous, but not efficient (Yejong silrok (睿宗實錄 Annals of King Yejong), v.6, 29 June 1469). 
According to Lee Mun-geon's Mukjae ilgi, one hundred years after the national medical system was considerably improved, local medical students still did not dedicate themselves to medical education. Local government offices gave them miscellaneous work from their offices and, therefore, failed to provide sufficient education. For these reasons, Lee Mun-geon counseled local residents on medical care and treatment and sometimes gave advice to medical students (Kim, 2001: 49-54; Shin, 2014: 458-459).

These medical circumstances-including, specifically, the shortage of doctors-increased the need for drugs. In particular, people used drugs for which they did not need to depend on doctors. These were called 'common medicines' (representative drugs). ${ }^{10)}$

\section{2) Abuse of Cheongsimwon}

The shortage of doctors that plagued the medical system during the first half of the Joseon era produced a widespread blind faith in drugs proven effective. The most commonly used representative drug was Cheongsimwon, which was widely used for stroke-related and other diseases. The people's faith in this medicine is illustrated to its use by the king in an urgent and treatment-irrelevant medical situation right before he died. ${ }^{11)}$

Specifically, on his way from a hot spring to the palace, King Taejong

10) A 'common medicine or representative drug' (通治) was used regardless of the symptoms of a specific illness. Its technical term can be seen in Donguibogam (東醫寶鑑 Exemplar of Korean Medicine). Since representative drugs had the advantage of being available and applicable without medical knowledge, they were very effective and widely used in the doctor-deficient Joseon Dynasty.

11) Taejong silrok (太宗實錄 Annals of King Taejong), v.15, 24 May 1408; Munjogn silrok (文宗實錄 Annals of King Munjong), v.13, 14 May 1452. Etc. 
KIM Seong-su: From Woohwang Cheongsimwon (牛黄淸心元) to Ginseng (人衤)

- The History of Medicine Use in the Joseon Era -

bestowed Cheongsimwon on a person hurt by a horse. ${ }^{12)}$ The definitely had a bruise from the impact with the horse, and likely lost consciousness due to the shock. However, it is unclear whether the doctor accompanying the king offered Cheongsimwon only because that was all he had or because he felt it appropriate for a patient who was semiconscious.

There are cases of Cheongsimwon being used for different diseases in a variety of records from Sejong's era. The following article is noteworthy because it illustrates how people perceived Cheongsimwon and other emergency remedies as panaceas.

Seungjeongwon (承政院 the Royal Secretariat) reported, "Generally, the way to treat a disease using drugs is to administer appropriate drugs to symptoms. However, people do not care about the origin of diseases, and when they come down with some urgent disease, they use Cheongsimwon. To use it in such a way is wrong. Cheongsimwon is largely used to save patients with nervous disorders, and therefore it should not be taken for a long time." ${ }^{13)}$

The Royal Secretariat emphasized that appropriate diagnosis and prescription practices were the proper processes for engaging in medicinal use. He also reported the frequency with which such principles were ignored and Cheongsimwon was used for a variety of diseases without considering their origin. ${ }^{14)}$ The extract also shows that-though Cheongsimwon was a

12) Taejo silrok, v.2, 13 October 1401.

13) Sejong silrok, v.91, 11 November 1440.

14) While this may simply be a problem of abuse, the abuse was due to excessive expectations of Cheongsimwon. Therefore, in addition to illustrating a case of abuse, this article can be said to provide information on common perceptions of drugs in the early Joseon Dynasty. 
drug that was largely used for nervous diseases and first aid and, thus, was dangerous when taken over a long period of time-people did not follow this principle. This overuse created a widespread social issue that worried the Royal Secretariat.

The overuse of Cheongsimwon also led to other side effects. Cheongsimwon contained many medicinal ingredients that were not produced domestically and were, therefore, hard to secure and very expensive. ${ }^{15)}$ As a result, those who lacked personal connections or could not afford true Cheongsimwon frequently used shoddy drugs, such as improperly made Cheongsimwon. It was possible that some individuals, after witnessing the popularity of Cheongsimwon, privately produced and sold it. The same was true of the drugs Sohapwon (蘇合元) and Bomyeongdan (保命丹), both of which (like Cheongsimwon) could be used to treat diverse symptoms. Given the widespread use of these drugs, their limited availability, and their high cost, medical institutions, nonmedical institutions, and unauthorized people often illegally manufactured these medicines.

The state, which monopolized the sale of drugs, could not overlook this situation. Therefore, the Royal Secretariat strongly argued for countermeasures and discussed methods to prevent the illegal production of Cheongsimwon. First, the state forbade the production of Cheongsimwon in any place other than state-established medical institutions. This prohibition of private production, which limited the supply of Cheongsimwon, was expected to rapidly increase its price of the drug. ${ }^{16)}$ To prevent this, the

15) Sejong silrok, v.29, 28 August 1425.

16) Sejong silrok, v.91, 22 November 1440. 
KIM Seong-su: From Woohwang Cheongsimwon (牛黄淸心元) to Ginseng (人蓼)

- The History of Medicine Use in the Joseon Era -

state also readjusted the drug's price. ${ }^{17)}$

However, the prohibition on the unauthorized production of Cheongsimwon was only a short-term policy. As a long-term and more credible method, efforts were also made to nurture reliable doctors who could provide proper diagnosis and treatment, which would help prevent the overuse of Cheongsimwon and similar medicines. ${ }^{18)}$ Though this second initiative was a priority at the national level, the king and policy makers struggled to bring its objectives to fruition.

The King ordered Yejo. "Korean doctors do not precisely know medical techniques. When examining patients' diseases, they do not refer to prescription books and do harm to lives, making careless judgments of their own and thinking there is no harm. From now on, have them not lightly say there is no harm after examination and carefully treat patients by referring to prescription books in detail. ${ }^{19)}$

The effort to reduce drug abuse sought to shift people's trust from drugs to doctors. To accomplish this goal, the king ordered that young and brilliant persons be selected and nurtured as doctors and that their qualifications should be improved through sufficient education and learning from medical books. ${ }^{20)}$

17) Sejong silrok, v.90, 28 July 1440; Seongjong silrok (成宗實錄 Annals of King Seongjong), v.23, 18 October 1472 .

18) Danjong silrok (端宗實錄 Annals of King Danjong), v.13, 25 January 1455; Sejo silrok (世 祖實錄 Annals of King Sejo), v.30, 22 May 1463; Seongjong silrok, v. 16, 14 March 1472; Seongjong silrok, v.226, 7 March 1489.

19) Sejong silrok, v.108, 22 May 1445.

20) Danjong silrok, v.12, 22 August 1454; Sejo silrok, v.5, 26 August 1456. 


\section{3) Fundamental Limitation of Medicines}

The relationship between categorized diseases and treatment drugs assumed that one kind of drug may treat one symptom resulting from a certain etiology. This concept-that a single-medicine prescription of a particular drug could treat a disease-was illustrated through specific cases in Hyangyak jipseongbang (鄉藥集成方 Compilation of Native Korean Prescriptions), which was published during Sejong's era.

Hyangyak jipseongbang was completed. The King ordered Kwon Chae (權探) to write its preface. "From the periods of Shennong (神農) and Huangdi (黃帝), there have medical officers to treat all the people. When a good doctor treated a patient with medicine, he did not insist on a specific medication, but prescribed it according to the patient's condition. Because customs, vegetation, and favorite food were different, depending on the region. ${ }^{21}$

This preface to Hyangyak jipseongbang mentioned 'regionality' to increase the utilization of domestic medicines, which were medicinal herbs produced in Joseon. It also spoke of cases in which single diseases were treated with particular types of medicinal herbs (Lee, 2011: 243-278). What the text sought to emphasize was not the name or type of any specific disease, but the understanding that diseases were cured by medicinal herbs.

This concept was expanded into a discussion on efficacy with regard to the expectation that medicinal herbs could be utilized in a complex way to treat different symptoms, as well as a fundamental etiology, when

21) Sejong silrok, v.60, 11 June 1433. 
KIM Seong-su: From Woohwang Cheongsimwon (牛黄淸心元) to Ginseng (人蓼)

- The History of Medicine Use in the Joseon Era -

treating a disease with two or more symptoms. This assumption served as a theoretical ground for complex prescriptions using diverse medicinal herbs and was tempered by the understanding that, when employing different medicinal herbs, their interactions should be sufficiently considered.

The understanding that one type of drug treats one symptom and that a complex prescription can treat a disease with multiple simultaneous symptoms indicated a need for caution when selecting drugs for a complex prescription, as illustrated in the following:

\begin{abstract}
King Seongjong (成宗) ordered the Royal Secretariat: "I looked at medical books and noticed that a drug largely treated one kind of disease, and there was no drug treating multiple diseases. When one experiences different symptoms due to bad foods or a sore heart, abdomen, or lumbar region, only one kind of drug treats only one kind of disease. If those with such multiple symptoms take drugs appropriate for them, they will recover quickly. However, if drugs are incompatible with each other, it is good to add other drugs or subtract some drugs. I intend to create such drugs and try them on people." ${ }^{22)}$
\end{abstract}

The fact that King Seongjong held this opinion of medicine suggests that knowledge about the relationships between diseases and drugs was very common in the late 15 th century. At the time, education for doctors had been strengthened, measures to secure medicinal herbs were being sought, and numerous policies to promote medicine were proposed (Kim, 1993: 253-254). If nurturing doctors was a fundamental solution for expanding medical care, the development of drugs, as attempted by Seongjong, can be understood as a measure to rapidly resolve real-world problems. In

22) Seongjong silrok, v.174, 22 January 1485. 
other words, Seongjong attempted to somewhat alleviate the shortage of doctors by developing drugs that used various medicinal herbs for different symptoms.

However, while drugs were used as medicines for treating diseases, they were also poisons. This had been a common view since the writing of Shennong bencaojing (神農本草經 Shennong's Classic of Materia Medica), which was published in Ancient China and formed the basis of contemporary knowledge regarding East Asia's traditional medicine and medicinal herbs (CaO, 2012: 172-174). Joseon scholars knew the classification of drugs into three different kinds' (sampumbunryu 三品分 類) for medicinal herbs presented by Shennong Bencaojing. Lee Seon-je's (李先齊) written proposal to Danjong (端宗), the 6th king of Joseon, clearly indicates such an understanding. ${ }^{23)}$

After explaining the classification of drugs, he cited Sun Si-miao (孫思 彩), a noted doctor of the Dang Dynasty, stressing that a liriopis tuber (天門冬) was a wonderful drug for a long and healthy life. According to Shennong Bencaojing, a liriopis tuber belonged to the high grade of medicine. Thus, Lee Seon-je explained that a liriopis tuber did not harm people, even if they took it for a long period of time. He added that such tubers could even improve energy, sometimes allowing people to become Taoist hermits with miraculous powers.

Lee Seon-je had several reasons for his remarks. Although the exact reason for this is unknown, at the time of Lee Seon-je's proposal, King Danjong was taking Buja ijungtang (附子理中湯). Given that it was winter and considering the efficacy of the decoction, it seems likely that Danjong

23) Danjong silrok, v. 4, 25 December 1452. 
KIM Seong-su: From Woohwang Cheongsimwon (牛黄淸心元) to Ginseng (人蒋)

- The History of Medicine Use in the Joseon Era -

caught the flu. Lee Seon-je strenuously objected to the utilization of Buja ijungtang because the herbs used for the drug were middle-and low-grade medicinal herbs, according to the Shennong bencaojing's classification

I heard that the Palace Medical Office prepares and offers Buja ijungtang. Aconite lateralis preparata radix (附子) is bitter, has a warm energy, triggers a lot of heat, and has much poison. Zingiberis rhizoma (乾薑) is also bitter, has a warm energy, and triggers a lot of heat. These two drugs are middle and low grade drugs according to Bencaojing, triggering heat and having poison. ${ }^{24)}$

Lee Seon-je emphasized using care when administering drugs because he believed that even treatment drugs were essentially poisonous. Therefore, he argued that even appropriate medicines should only be used for a short time to treat a disease and should not be overused, even when a patient was not very sick. In actuality, though fashionable drugs like Cheongsimwon and liriopis tubers had medicinal properties, they were also dangerous when taken over a long period. In addition to the danger of selecting and taking medicinal herbs over long periods, it was also necessary to consider their price. Taking medicines for a long period of time was not possible for every social class.

However, contemporary views largely corresponded with the East Asian traditional medicinal principle of prevention: treatment should be provided before the outbreak of a disease. This logic of health preservation, in which people sought to prevent disease by providing sufficient energy for the body, formed another axis of contemporary medical theory. Gradually,

24) Danjong silrok, v. 4, 25 December 1452. 
KIM Seong-su: From Woohwang Cheongsimwon (牛黃淸心元) to Ginseng (人蓼) -The History of Medicine Use in the Joseon Era-

however, opportunities arose to change the discourse on medicines popular during the first half of the Joseon era.

\section{The Combination of Self-cultivation and Ginseng}

\section{1) Expansion of Self-cultivation as Practice}

The theory of health preservation or self-cultivation gave birth to a new perception regarding the utilization of drugs since the 16th century. The theory of health preservation satisfied people's desire for health management, difficult to achieve even with panaceas. The theory of health preservation also changed the central idea of medicine, shifting the general approach from 'treatment after the occurrence of a disease' (ibyeongjichi 已 病之治) to 'treatment before the occurrence of a disease' (mibyeongjichi 未 病之治). It was certainly understood, however, that not all problems could be solved with drugs. In the early 16th century, King Yeonsangun(燕山君) gave the following order to his subjects:

The king ordered. "There is an old proverb "the pine and the nut pine do not change even though it is cold" but they do not survive long, let alone humans. When humans are born, there is necessarily death, but how can they avoid it with drugs? If drugs cannot save people, what is the use of Napyak (臘藥) $?^{25)}$ Therefore, don't give me Napyak. ${ }^{26)}$

As he said, however well people might be treated, there is no solution

25) Napyak refers to medicine produced during December of the lunar calendar year, which the king gave his servants as a symbol of mercy at the end of the year. Shin Dong-won, "Napyak, 'Un hae nap yak zung chi bang', and Hur jun”. The Journal of Korean Medical History 14-2, 2001, pp. 23-8.

26) Yeonsangun ilgi (燕山君日記 Annals of King Yeonsan), v.60, 29 December 1505. 
KIM Seong-su: From Woohwang Cheongsimwon (牛黄淸心元) to Ginseng (人衤)

- The History of Medicine Use in the Joseon Era -

for death. Instead, the fundamental concern was how to maintain an individual's lifespan, which was believed to be determined by Heaven. This concern led to the growth of the theory of health preservation.

The theory of health preservation was introduced during the early Joseon Dynasty, but it did not spread widely until the 16th century. This century witnessed a significant growth of yangban living in the villages, resulting in the development of the economic land ownership system. In addition, the kingdom was operating at a chronic deficit, and training program for health workers, such as Uiseo Seupdoggwan (醫書習讀官), were shrinking.

For these reasons, though a number of Confucian scholars participating in medical activities appeared in 16th century villages, the preservation theory was popularized in a situation with little professional medical education. These circumstances were illustrated by the prescription doctors offered to King Seonjo.

The medical official of the Naeuiwon (內醫院 the Medical Center for the Royal Family) of the Joseon Dynasty finished his medical care and said. "This is because the spleen and stomach are weak and the upper body is hot, the lower body is cold, and nutrition is insufficient but labor is excessive, which makes consumptive fever go up. You should continue to eat delicious food to invigorate vitality so that it does not drop and do not do labor and take rest, preventing fever. If you do not have regular meals, your health will be worse later." ${ }^{27)}$

In other words, to preserve the King's health, the doctor prescribed that he should rest, refrain from excessive labor, and seek to invigorate his vitality. Although he prescribed drugs, such as Samseongo (三仙糕) and

27) Seonjo silrok (宣祖實錄 Annals of King Seonjo), v.9, 25 February 1575. 
Saengmaeksan (生脈散), he also prescribed improvements and adjustments to physical strength and ordinary life.

Doctors at the Medical Center for the Royal Family read subtle changes in the king's body and tried to figure out the etiology of his disease, which may have been latent in his internal organs. Before the king's condition progressed into a disease, they planned a treatment involving foods and appropriate rest. This approach differed significantly from those taken during the first half of the Joseon era, as the tendency to utilize medicine appeared. Although this case is undoubtedly different from the typical experience of an ordinary person during the Joseon era, in that the object of medical care was the king, it is notable that the doctors began treatment before any particular disease was revealed.

This anecdote illustrates the growing strength of people's belief in the principle that treatment should be made before one develops a disease, as written in ancient medical scriptures. The change was also affected by the fact that, as the theory of the preservation of health spread during the first half of the Joseon era, people's knowledge of health and diseases also changed. Moreover, due to continuous efforts to nurture doctors during the first half of the Joseon era, doctors' qualifications improved, and they got to understand subtle changes and disease etiologies.

The combination of medicine and the theory of health preservation is more obviously revealed by the publication of Donguibogam (Kim, 2000: 136-142), written and published by Heo Jun (許浚), which was set against the background of the intellectual class's preference for the theory of health preservation, as represented by King Seonjo (宣祖). These circumstances are explained in book's preface. 
KIM Seong-su: From Woohwang Cheongsimwon (牛黄淸心元) to Ginseng (人蒋)

- The History of Medicine Use in the Joseon Era -

In the year of 1596 King Seonjo called the royal physician of the Medical Center for the Royal Family, Heo Jun, and said, "Recent Chinese books on medicine are all trifle stuff that are merely copies and not worth reading. All medical books ought to be gathered into one book. People's diseases all come from the inappropriate care of their health, so the subjects about cultivation should come first, and the subjects on herbs and acupuncture should come later. Most medical books are too vast and complex, so only the essentials shall be selected." 28

It is commonly believed in the academic world that Taoism's theory of health preservation was actively accommodated due to the characteristics of Donguibogam, it is noteworthy that King Seonjo was the individual who mandated this accommodation. The grafting of the theory of health preservation onto medicine also reflected the flow of ideas in the intellectual world (Kim, 2000: 161-174).

Although the king ordered that the book address self-cultivation, Donguibogam was certainly a medical book. Therefore, in addition to discussing self-cultivation on a superficial level, Heo Jun also explained it in medical terms. Unlike other medical books, Donguibogam assigned significant space to the invigoration of vital force. Based on the integration of the medical theories of Zhu Zhen-heng (朱震亨) and Li Gao (李杲), ${ }^{29}$ Heo Jun intended to embody the measures for 'nourishing ying qi' (jiyin 滋陰) and 'nourishing the stomach' (yangwei 養胃) according to the composition of jing (semen 精)-qi (氣)-shen (spirit 神). In “Sinhyeong”

28) Kim Nam-il et al trans, "Preface," Donguibogam, Part1, 2013, p.1.

29) Li Gao noted that the preservation of health was a factor related to all diseases caused by a weakened body. Meanwhile, Zhu Zhen-heng argued that self-cultivation to restrain from desires was necessary in order to maintain insufficient ying qi (陰氣) of the kidneys (Maeng, 2001: 154-55, 238-43). 
(身形), the first section of Donguibogam, Heo Jun identified drugs that made people healthy and helped them to live a long time, including Gyeongokgo (瓊玉膏; which is still widely used), Samjeongwhan (三精丸), and Yeonnyeoniksu bulrodan (延年益壽不老丹). These were drugs that invigorated the body. ${ }^{30}$

\section{2) Restorative Herbal Medicines and Ginseng}

The logic of invigoration presented in Donguibogam had a major influence on the latter half of the Joseon era because it corresponded with the medical theory of Huangdi neijing 黃帝內經(Internal Classic of the Yellow Emperor): that 'treatment before the occurrence of a disease' was the best treatment. This trend was particularly noticeable in the treatment of the king and the royal family. Although it is important to consider the special position of the king, it is also notable that the central focus of medicine transferred from the treatment of diseases to the treatment of health before the outbreak of disease. This shift was accompanied by a subsequent change in the use of drugs.

Restorative herbal medicines became fashionable among kings during the latter half of the Joseon era. For example, King Seonjo took restorative herbal medicines due to a lack of energy while receiving treatment for a cough, and King Hyeonjong (顯宗) used Whanggiinsamcha（黃芪人衤 茶) and Bojungikgitang (補中葐氣湯) as restorative herbal medicines. The Medical Center for the Royal Family recommended that King Gyeongjong (景宗) continue to take Gongjindang（供辰丹), which contained Chinese muschus. In particular, King Yeongjo was famous for taking ginseng

30) Kim Nam-il et al trans, "Internal Bodily Elements," Donguibogam, Part1, 2013, pp.40-43. 
KIM Seong-su: From Woohwang Cheongsimwon (牛黄淸心元) to Ginseng (人衤)

- The History of Medicine Use in the Joseon Era -

for a long time, and the amount he took between the ages of 59 and 73 exceeded 100 geuns. King Yeongjo loved ginseng so much that he took approximately 20 geuns in a single year when he was 72 years old (Kim, 2005: 111).

The tendency to prefer restorative herbal medicine grew even stronger in the 18th century. This tendency is illustrated by a conflict of opinion between King Jeongjo (正祖) and his doctors during this time. When King Jeongjo's furuncle worsened and he developed a severe fever, his doctors preferred restorative herbal medicines, such as Gyeongokgo and Saengmaeksan, while King Jeongjo insisted on cold medicines instead. ${ }^{31)}$

Arguing that using cold medicine was improper, the doctors continued to recommend drugs that would invigorate vitality and improve the blood, such as Samultang (四物湯), Yukgunjatang (六君子湯), Palmultang (八 物湯), and Gyengokgo, a restorative herbal medicine. However, King Jeongjo rejected warm medicines, arguing that they were not suitable for his physical constitution.

This confrontation between the doctors and the king was not solely rooted in their differences in medical opinions. If the king's disease had worsened or he had died, the doctors would have been held responsible. In severe cases, it was common that doctors who failed in their duty to the king were put to death. This was the case with Doctor Gang Myeong-gil (康 命吉), who was most trusted by King Jeongjo and who was held responsible and put to death when the king died. ${ }^{32)}$ Therefore, providing treatment to the king was very burdensome, and this burden certainly played a role in the conflict between the doctors and King Jeongjo. Nevertheless, the root

31) Jeongjo silrok (正祖實錄 Annals of King Jeongjo), v.54, 26 June 1800.

32) Sunjo silrok (純祖實錄 Annals of King Sunjo), v.1, 1 August 1800. 
of the conflict lay in the two parties' differences in viewpoints regarding responding to diseases and using drugs.

The tendency to prefer restorative herbal medicine was common among ordinary people as well as the king. As mentioned earlier, this trend appears to have been influenced by the presentation of the practice drug use to invigorate oneself in Donguibogam and the "tending to prescribe the warming and tonifying medicine' (Wenbuxuepai 溫補學派) during the Ming Dynasty (Oh, 2014: 9-10). Just as King Yeongjo used ginseng, it became widely used among ordinary people in the 18th century. For example, Yu Man-ju (兪晚桂), who lived in Hanyang in the late 18th century, said the following in his diary, Heumyeong (欽英):

50 or 60 years ago, it was common to use rhei rhizome (大黃) or natrii sulfas (芒硝) in treating a disease and rare to use aconite lateralis preparata radix (附子) or cinnamomi cortex (肉桂). These days, ginseng, cervi parvum cornu (鹿茸), aconite lateralis preparata radix, and cinnamomi cortex are commonly used and bupleuri radix (柴胡) and scutellariae radix (黃芩) are rarely used. $^{33)}$

Yu Man-ju pointed out that 50 or 60 years before he wrote his diary in 1778, drug use had greatly changed from a focus on cold drugs, such as rhei rhizome and natrii sulfas, to restorative herbal medicine, such as ginseng and cervi parvum cornu, or warm drugs, such as aconite lateralis preparata radix and cinnamomi cortex. As these new trends became more popular, people began to believe that treatments that did not use certain ingredients were not drugs. ${ }^{34)}$

33) Heumyeong, 17 September 1778.

34) Heumyeong, 6 July 1786. 
KIM Seong-su: From Woohwang Cheongsimwon (牛黄淸心元) to Ginseng (人衤)

- The History of Medicine Use in the Joseon Era -

This perception was especially true for ginseng. ${ }^{35)}$ Yu Man-ju described the phenomenon as follows.

Ginseng is the number one treasure in this nation, in this century. Generally right now, usage of ginseng is very extreme, and its cost is very high. At the end of Sukjong's reign (1674-1720), one don (3.75 grams) of ginseng was worth three or four nyangs [a unit of old Korean coinage]. However, at the beginning of Yeongjo's reign (1724-1776), it was not considered as expensive, even though cost was the same. Ever since Yeongjo took ginseng, the best ginseng, which was served to the king, cost from 50 to 60 nyangs for one don of ginseng. Also, inferior goods that noble in rural areas or high officials consumed worth 7-16 nyangs for one don of ginseng. In addition to those who were poor and low-class, everyone, including the ordinary class, enjoyed ginseng. This shows how the world has changed. ${ }^{36)}$

As a result, within ten years in the early 18th century, the price of ginseng increased more than tenfold, and the price of the best ginseng rose about two hundredfold (Kim, 2014: 114-119). The increased demand and high prices sparked efforts to find new ginseng production centers. Merchants

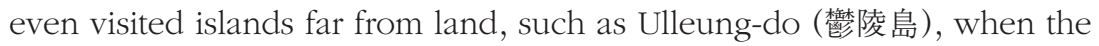
prevalence of ginseng in these areas became widely known ${ }^{37)}$

35) In these passages, ginseng indicates wild ginseng. Man-grown ginseng began to spread during the mid-to late-18th century and was triggered by increased needs for ginseng (Yeom, 2003: 153-182). Introduction of man-grown ginseng was triggered by increased needs for ginseng. In turn, the supply of man-grown ginseng increased the demand for ginseng.

36) Heumyeong, 9 July 1778.

37) Heumyeong, 13 October 1777. For reference, Ulleung-do is a South Korean island 120 $\mathrm{km}$ east of the Korean Peninsula. 
KIM Seong-su: From Woohwang Cheongsimwon (牛黃淸心元) to Ginseng (人蓼) -The History of Medicine Use in the Joseon Era-

\section{3) Why Ginseng is Widely Used}

Both patients and doctors during the 18th century appeared to prefer ginseng, as evidenced in Yeoksi Manpil (歷試漫筆 Stray Notes with Experienced Tests), written by I Su-gi (李壽祺), who worked as the Medical Center for the Royal Family (內醫院) in the mid-18th century. The book indicates that I Su-gi treated various diseases in more than 150 patient cases. It also reveals that he used ginseng in many of these treatments. In other words, I Su-gi frequently either prescribed medicines containing ginseng or used ginseng to strengthen the body after prescribing treatments using other ingredients.

Though, in some cases, prescription compositions were unclear, or a variety of therapies were prescribed for a single patient, 75 cases out of 150 included ginseng. ${ }^{38)}$ Furthermore, I Su-gi also used ginseng rather than cold prescriptions to lower the body temperature in cases of smallpox (or measles). ${ }^{39)}$

This trend toward ginseng use was the same among patients, who widely did not accept medicines not containing ginseng or deer antlers. Yu Man-ju criticized this phenomenon, using the term 'mode'

These days, physicians surely use ginseng, cervi parvum cornu, cinnamomi cortex and lateralis preparata radix. This is what modish doctors or modish medicines are. Other than

38) Among the prescriptions that Yi Su-gi used, cases including ginseng are as follows (case numbers listed in Yeoksi Manpil): 1, 3, 4-1, 5, 6, 7-1, 7-2, 7-3, 10, 11, 12, 13, 16, 19, 20, $25,26,27,28,33-1,34-1,34-2,40,42,45,46-2,47,48,49,50,51-1,54-1,54-2,54-3$, 55-1, 55-2, 55-3, 56-1, 56-2, 62, 63, 65, 66, 68, 70, 73, 77, 78, 79, 80, 81, 82, 83, 84, 85, 91, 95-1, 95-2, 97-2, 98, 107-1, 107-2, 112, 113, 115, 118, 122, and 130. There are some differences in the number of cases because some cases involved multiple prescriptions. In nine cases, prescriptions of only ginseng were given.

39) Shin Dong-won et al trans, Yeoksi Manpil, 2015, pp.32-36. 
KIM Seong-su: From Woohwang Cheongsimwon (牛黄淸心元) to Ginseng (人衤)

- The History of Medicine Use in the Joseon Era -

these, sufferers or people don't consider medicine as medicine. However, were theories of medical science or medicine ever like this before? Of course there are diseases that should be treated with ginseng, cervi parvum cornu, cinnamomi cortex and lateralis preparata radix, but there are also diseases that must not be treated with these. How can these be medicine when used so thoughtlessly? ? $^{40)}$

As Yu Man-ju stated, suitable medicine should be used for suitable treatment. Depending on the situation, for example, cold ingredients should also be used. Thus, even for Yu Man-ju, who was not a doctor, the widespread dependence on ginseng among patients and doctors raised serious concerns.

The preference for ginseng was largely due to the doctors of the late Ming Dynasty and their preference for warm prescriptions; however, it also reflected the conservative shift in medicine usage. Skilled doctors hesitated to use strong drugs and preferred gentle treatments, which led to the frequent use of ginseng and deer antlers, in the event of treatment failures. $^{41)}$

Conversely, some newer doctors tried to show their talent by using strong medicines to achieve faster cures (Kim, 2011: 9). However, such approaches involved significant risks. People like Yu Man-ju, who received medical information frequently and were in touch with many physicians, watched out for doctors who used strong medicines. ${ }^{42)}$

Many doctors were active in the 18th century Joseon, especially in

40) Heumyeong, 6 July 1786.

41) It is likely that Yi Su-gi usually prescribed ginseng because of this trend.

42) Yu Man-ju described in detail how Fan Yun (范雲) had died and the doctor's warning that, though a strong treatment might have cured him for a while, he would die two years later (Heumyeong, 22 July 1781). 
Hanyang. The city's expansion and growing population led to the growth in the number of active doctors. The expansion of the medical market also increased the number of doctors participating in medical activities. In the end, competition among them was inevitable, and many doctors sought safe treatments for stable operations. To accomplish this, many turned to the use of ginseng.

Though the common use of ginseng sparked many critics, so, too, did the indiscreet use of colder medicines. In the latter half of the 18th century, Jung Jong-ro (鄭宗魯) criticized doctors for using new, risky prescriptions to achieve quick results, instead of focusing on exorcising bad energies by reviving the patient's spirits as doctors had done in the past. ${ }^{43)}$

Negative perceptions of such practices were more common among the sick and in sick family. For example, Yu Man-ju, who was disheartened by the death of his younger sons, believed the death to be due to his doctor's continued prescriptions of cold medicines, such as rhubarb, plaster, menstrual blood, etc. ${ }^{44)}$ However, the death was actually due to the doctor's failure to diagnose the disease correctly and determine the most appropriate prescription.

Lee ik (李瀷) described the reality of the medical field as follows.

Today's doctors do not mind relieving dying people and only try to make money. Therefore, they always try firstly with a very hot medicine, such as ginseng and lateralis preparata radix, and if [these were] not efficacious, they prescribe extremely cold things, such as sodium sulphate and rhubarb. When a sick person survives, he shows off his power and does not regard it

43）Ipjjae Yugo (立齋遺稿), v.16, “An article on medicine 醫說”

44) Heumyeong, 15 May 1787. 
KIM Seong-su: From Woohwang Cheongsimwon (牛黄淸心元) to Ginseng (人蓼)

- The History of Medicine Use in the Joseon Era -

as a $\sin$ if he dies. ${ }^{45)}$

In conclusion, the popularity of ginseng was a social phenomenon created by sick people who favored safe treatments and demanded by doctors who pursued stable management methods to help them compete with other professionals in the growing medical field of the 18th century. Since the use of ginseng was closely related to the prevalence of restorative herbal medicine, it is no exaggeration to say that the use of drugs in the latter half of the Joseon era was dominated by restorative herbal medicine.

\section{Conclusion}

When our understandings of the human body and diseases change, so, too, do methods of treatment. When Western medicine entered the premodern Joseon society, such changes became immediately noticeable. Since then, Western medicine, which is based on scientific rationalism, has taken the predominant position in the medical field. Since methods of treatment determine people's lifestyles, the general trend in Korean life has been toward Westernization and rationalism in the cultural context of diseases and treatment. At the same time, impressions regarding premodern medicine and society have persisted.

Pre-modern medicine, a field that previously exhibited no noticeable change, has also begun to experience change, largely as a result of diverse attempts to spark a shift. Different aspects of disease coping and treatment have changed people's perceptions of drugs. In the early Joseon era, when

45) Korean translation of Seongho Saseol (국역 星湖僿說), v.9, “A quack kills people 庸醫 殺人” 
the popularization of medical knowledge was insufficient, many people were interested in using medicines like Cheongsimwon to treat a variety of illnesses. However, as the field of medicine developed, doctors were nurtured, and the theory of health preservation gradually spread, changes began to occur. Health maintenance, the ability to read subtle changes in health, and the provision of advance treatment were brought into focus alongside treatment responses to diseases. Finally, in the latter half of the Joseon era, the use of restorative herbal medicines, such as ginseng, was prevalent.

It is likely that such changes in drug use were largely confined to the upper class, since the class that employed drugs was already very small. Though restorative herbal medicines began to circulate during the latter half of the Joseon era, the myth of Cheongsimwon continued to exist among the classes that had difficulty securing drugs. ${ }^{46)}$ In addition, such families tended to use the quickest and least expensive treatments, rather than the moderate treatments with minor side effects pursued in restorative herbal medicine.

Thus, over the centuries, the face of medicine in Korea changed significantly in response to changes in social factors, such as medical accessibility, ideological and cultural understandings, and the co-existence of diverse types of medicine. In particular, as the theory of health preservation and the use of medicine for disease treatment were combined in the latter half of the Joseon era, the medical world came to prefer restorative herbal medicine, which is still influential characteristic in the

46) Jeong Yak-yong (丁若鏞), describing the efficacy of Cheongsimwon and Sohapwon, advised always preparing these medicines (Yeoyudang jeonseo 與唒堂全書, medical section v.5, "idle talk 雜說 3"). 
KIM Seong-su: From Woohwang Cheongsimwon (牛黄清心元) to Ginseng (人蓼)

- The History of Medicine Use in the Joseon Era -

world of traditional Korean medicine. While restorative herbal medicine is positively associated with health, its growing popularity weakened the essence of medicine: treatment. Despite the popular faith in drugs, analytical medicine, which places drugs at the forefront, failed to emerge. As a result, numerous opportunities for development in Korea's traditional culture of drugs were missed.

Key words: Cheongsimwon, Ginseng, Self-cultivation, Restorative Herb Medicine

Received: 2017.07.05 Reviewed: 2017.07.11 Accepted: 2017. 07. 29 
KIM Seong-su: From Woohwang Cheongsimwon (牛黃淸心元) to Ginseng (人蔘) -The History of Medicine Use in the Joseon Era-

\section{REFERENCES}

\section{〈Primary sources〉}

Huangdi neijing (黃帝內經 Internal Classic of the Yellow Emperor) (Yao Chunpeng (ed), Beijing: Zhonghua shuju, 2010)

Shennong bencaojing (神農本草經 Shennong's Classic of Materia Medica) (Shanghai: Shanghai guji chubanshe, 1995-2002)

Hyangyak jipseongbang (鄉藥集成方) (Seoul: Hanglim chulpansa, 1977)

Heo, Jun (許浚 1539-1615), Donguibogam（東醫寶鑑 Precious Mirror of Eastern

Medicine) (Kim Nam-il et al, English Translation of Donguibogam, Seoul: Ministry of Health \& Welfare, 2013)

Joseon wangjo silrok (朝鮮王朝實錄 The Annals of the Joseon Dynasty) (Gwacheon: National Institute of Korean History, 1970) Digitized and on-line at http: //sillok. history.go.kr/

Lee, Mun-geon (李文楗 1494-1567), Mukjae ilgi（默齋日記）（Gwacheon：National Institute of Korean History, 1998)

Lee, ik (李瀷 1681-1763), Seongho Saseol (星湖僿說) (Seoul: Institute for the Translation of Korean Classics, 1982)

Jung, Jong-ro（鄭宗魯 1738-1816), Ipjjae yugo (立齋遺稿) (Seoul: Institute for the Translation of Korean Classics, 1998)

Yu, Man-ju（俞晚柱 1755-1788), Heumyeong (欽英) (Seoul: Kyujanggak Institute for Korean Studies, 1997)

Jeong, Yak-yong 丁若鏞 (1762-1836), Yeoyudangjeonseo (與猶堂全書) (Seoul: Institute for the Translation of Korean Classics, 2002)

〈Secondary sources〉

Cao, Zhi-ping 曹志平, The History of Logic in Chinese Medicine 中國醫學論理思想史 (Beijing: People's Medical Publishing House, 2012).

Oh, Chaekun, "The Cold Damage Medicine in 17th and 18th Century Korea: Comparison through the Medical Records of China, Japan, and Korea," Historia Scientiarum 24-1 (2014).

Kim, Du-jong 金斗種, Medical History of Korea 韓國醫學史 (Seoul: Tamgudang, 1993). Kim, Ho 金湖, “Hygiene and Medical Life of Sajok 士族 Who Lived in Seoul in the Late 
KIM Seong-su: From Woohwang Cheongsimwon (牛黄淸心元) to Ginseng (人蓼)

- The History of Medicine Use in the Joseon Era -

18th Century of the Chosun Dynasty-Especially Focusing on Hum-Young 欽英,”

The Journal of Seoul Studies 서울학연구 11 (1998).

Kim, Ho, The Study about Donguibogam of Hur Jun 허준의 동의보감 연구 (Seoul: Iljisa, 2000).

Kim, Jeong-seon 金正善, "Medicine Reflected in the Treatments of the Kings in the Chosun Period," PhD diss., Seoul National University, 2005.

Kim, Seong-su 金聖洙, “Local Medicine and the Counteraction of the Sajok 士族 in the 16th Century,” The Journal of Korean History 韓國史䃑究 113 (2001).

Kim, Seong-su, "The Actual Management of the Central Medical Institutions in the 16th and 17th Centuries," The Journal of Seoul Studies 서울학연구 20 (2003).

Kim, Seong-su, "Re-evaluation of the Medical Practice and the Medicine in the Later Half of the Chosun Dynasty," Korean Journal of Medical History 의사학 18-1 (2009).

Kim, Seong-su, "Study about the Formation of Doctors' Identity in the Joseon Dynasty," Korea Journal of Oriental Medicine 한국한의학연구원논문집 17-2 (2011)

Kim, Seong-su, "The Medical Changes in the Late 18th Century - Medicine of the Late Joseon Era Examined with Heumyeong 欽英,” Korean Culture 韓國文化 65 (2014).

Lee, Jin-su 李鎮洙, “A Study of Conceptional Establishment of Man’s Well Being During Chosun Dynasty,” Journal of Seokdang Academy 石堂論叢 9 (1984)

Lee, Jin-su, “A Study of Conceptional Establishment of Man's Well Being During Chosun Dynasty (Part II-Centered Consideration on Dong Eui Bo Gam-), Journal of Seokdang Academy 石堂論叢 10 (1985)

Lee, Kyu-dae, "Study about the Medical Mutual Assistance Association in the Late Joseon Dynasty," The Collection of Historical Treatises (celebrate the retirement of Dr. Kim Yong-deok) 史學論叢 (又仁金龍德博士停年紀念), (Seoul: Taegwang Munwhasa, 1988)

Lee, Kyung-Lock, "From Hyangyak to Dongui: The Medical Theory of the Hyangyakjipseongbang and Korean Traditional Medical Practice," The Korean Historical Review 한국사연구 212 (2011)

Li, jingwei 李经纬 and Zhang, zhibin 张志斌 et al., The History of Chinese Medical Thoughts 中医学思想史 (Hunan: Hunan Education Press, 2003)

Liu, Chang lin 劉長林. Kim, Su Jung et al trans., Huangdi neijing 1 · 2 (Seoul: Cheong- 
KIM Seong-su: From Woohwang Cheongsimwon (牛黃淸心元) to Ginseng (人蓼) -The History of Medicine Use in the Joseon Era-

hong, 2011)

Ma, Bo-Ying 馬伯英, A History of Medicine in Chinese Culture 1 - 2 中國醫學文化史 上·下 (Shanghai: Shanghai renmin chuban she, 2010)

Maeng, Ung-jae et al., Various Schools of Traditional Chinese Medicine 各家學說 (Seoul: Daesung Publishing Company, 2001)

Shin, Dong-won 申東源, Doctor of Joseon Dynasty, Heo Jun 조선사람 허준 (Seoul: Hangyeore Press, 2001)

Shin, Dong-won, "Medical Practitioners in Korea from the Late Seventeenth to the Nineteenth Centuries," Journal of the Korean History of Science Society 한국과 학사학회지 26 (2004a)

Shin, Dong-Won, Cholera, Attacked Joseon Dynasty 호열자, 조선을 습격하다 (Seoul: Critical Review of History Press, 2004b)

Shin, Dong-won, "The Transformation of Everyday Medical Life between the Late 16th Century and the Late 18th Century: From 'Gift' Economy to Market Economy," Critical Review of History 역사비평 75 (2006a)

Shin, Dong-Won, "Three Great Phases in the Development of the Local Medical System of the Joseon Dynasty," The Journal of Korean History 한국사연구 135 (2006b)

Shin, Dong-won, "How Commoners Became Consumers of Naturalistic Medicine in Korea, 1600-1800," Technology and Society 4-2 (2010)

Shin, Dong-Won, Medicine Life History in Joseon 조선의약생활사 (Paju: Dulnyouk Publishing Co, 2014)

Shin, Dong-won et al trans., Yeoksi Manpil 역시만필 (Paju: Dulnyouk Publishing Co, 2015)

Son, Hong-yeol 孫弘烈, A Study on Medical System of Medieval Korea 韓國中世의 醫療 制度研究 (Seoul: Suseowon, 1988)

Yeom, Jeong-sup, "The development and diffusion of ginseng in 18th century," Collection of Treatises in National Institute of Korean History 國史館論叢 102 (2003) 


\title{
From Woohwang Cheongsimwon (牛黄清心元) to Ginseng (人蓼)
}

\section{-The History of Medicine Use in the Joseon Era-}

\author{
KIM Seong-su*
}

In Korean traditional medicine, though herbal decoction, acupuncture, and moxibustion are all used to treat diseases, restorative medicines are the most widely preferred treatment method. This paper explores the historical background of restorative herbal medicines and ginseng among the Korean public and Korean traditional medicine practice. It also seeks to clarify how social and cultural perspectives on drug use have changed since restorative medicine became mainstream during the Joseon era.

Drug use tendencies were affected by the medical system of the Joseon Dynasty, patients' desires for reliable treatment, and perceptions of the human body and the causes of disease. In the late Joseon Dynasty, medicine, an industry originally monopolized by the government, began to be manufactured and traded on the free market, and medical personnel began to participate in medical activities on a large scale. As the healthpreserving theory became more popular and medical personnel became more accessible, medicinal preferences also changed.

\footnotetext{
* Seoul National University, Seoul, KOREA

E-mail: imsskim@snu.ac.kr
}

Received: Jul. 05, 2017; ～Reviewed: Jul. 11, 2017; $\quad$ Accepted: Jul. 29, 2017 
Specifically, whereas preference was first given to common medicines, such as Cheongsimwon, which are effective for various symptoms, restorative medicines, such as ginseng, gradually became more popular. These restorative medicines were faithful to the basic tenet of East Asian traditional medicine: to avoid disease by making the body healthy before the onset of illness. Patients' desires for safe treatment and growing competition among commercial doctors who wanted stable profits further increased the popularity of milder medicines. Ultimately, as ginseng cultivation was realized, its use expanded even further in a wave of commercialization.

Key words: Cheongsimwon, Ginseng, Self-cultivation, Restorative Herb Medicine 
